\author{
Renata Karkowska \\ Uniwersytet Warszawski \\ e-mail: rkarkowska@wz.uw.edu.pl
}

\title{
ZWIĄZEK NIETRADYCYJNEJ DZIAŁALNOŚCI BANKÓW I ICH STABILNOŚCI W KONTEKŚCIE RESTRYKCYJNOŚCI REGULACJI BANKOWYCH*
}

\section{THE RELATIONSHIP BETWEEN NONTRADITIONAL BANKING ACTIVITY AND THEIR STABILITY IN THE CONTEXT OF RESTRICTIVENESS OF BANK REGULATIONS}

DOI: $10.15611 / \mathrm{pn} .2018 .531 .19$

JEL Classification: G20, G21, G32, G33

Streszczenie: Łączenie tradycyjnej działalności bankowej z działalnością inwestycyjną, jaką jest obrót papierami wartościowymi czy sekurytyzacja, może przynosić zmniejszenie stopnia ryzyka banków komercyjnych. Badacze są jednak bardziej ostrożni i wskazują, że wprawdzie wzrost uniwersalności działalności bankowej może potencjalnie zmniejszyć ryzyko, ale jednak korzyści, wynikające z dywersyfikacji produktów, są ograniczone. Celem artykułu jest weryfikacji pytania badawczego: W jakim zakresie dywersyfikacja tradycyjnej działalności banków komercyjnych wpływa na ich stabilność? Analiza została poszerzona o znaczenie czynników specyficznych dla danego kraju, tj. restrykcyjność regulacji bankowych, jakość monitoringu inwestorów oraz skuteczność działania nadzoru finansowego. Badanie zostało przeprowadzone na próbie 9400 banków komercyjnych w skali globalnej, wykorzystano dane statystyczne z okresu 1996-2011. Istota poruszanego problemu znajduje zastosowanie w prowadzeniu polityki strukturalnych przedsięwzięć reformujących system bankowy, w tym próbie rozdzielenia funkcji bankowości detalicznej i inwestycyjnej.

Słowa kluczowe: bankowość, ryzyko niewypłacalności, niestabilność finansowa, działalność pozaodsetkowa banków, regulacje bankowe.

Summary: The aim of the article is to verify the research question: how the diversification of the traditional activities of commercial banks affects their stability. The analysis has been extended by the importance of country-specific factors, i.e. the restrictiveness of banking regulations, the quality of investor protection and the effectiveness of financial supervision. The survey was conducted on a sample of 9.400 commercial banks on a global scale, using data

* Projekt zrealizowany w ramach 7 edycji konkursu NBP dla projektów badawczych i sfinansowanych przez NBP. 
from the period 1996-2011. The essence of the problem is applied to the policy of structural undertakings reforming the banking system, including attempts to separate the functions of retail and investment banking.

Keywords: banking, insolvency risk, financial instability, non-interest banking activities, banking regulations.

\section{Wstęp}

Segmentem rynku finansowego, który ze względu na swój charakter podlega w największym stopniu efektom zarażania niestabilnością ze strony systemu finansowego, jest sektor bankowy. Biorąc pod uwagę fakt, że ryzyko systemowe sektora bankowego może być efektem podjęcia przez banki niewłaściwych decyzji co do poziomu akceptowanego ryzyka, a także wynikać z kształtowania się czynników rynkowych, zasadne wydaje się przyjęcie założenia, że na poziom tego ryzyka w poszczególnych krajach oddziałują te same kategorie czynników, ale różna jest intensywność ich wpływu i reakcji zwrotnej pojedynczego banku lub całego sektora bankowego.

Motywacją do przeprowadzenia badania jest szybki rozwój bankowości konglomeratowej, stymulowanej synergią między tradycyjną a równoległą działalnością inwestycyjną banków, w okresie przed kryzysem finansowym lat 2007-2008. O skali tego zjawiska świadczyć może wzrost udziału dochodów pozaodsetkowych w działalności banków. Celem artykułu jest weryfikacja pytania badawczego: W jakim zakresie dywersyfikacja działalności banków komercyjnych poprzez wchodzenie w różne segmenty rynku wpływa na ich stabilność? Autor stawia pozytywną hipotezę o tym, że dywersyfikacja działalności banków powinna przyczyniać się do ich stabilności. Analiza została poszerzona o znaczenie czynników specyficznych dla sektora bankowego danego kraju, tj. restrykcyjność regulacji bankowych, jakość monitoringu inwestorów oraz skuteczność działania nadzoru finansowego.

Analiza ma charakter teoretyczno-empiryczny i składa się z czterech części: przeglądu literatury przedmiotu, prezentacji modelu i wyników dokonanych analiz oraz wniosków końcowych.

\section{Przegląd literatury}

Ewolucja systemów finansowych gospodarki zmierza w kierunku odejścia od bankowości tradycyjnej na rzecz bankowości inwestycyjnej i zarządzania ryzykiem. Proces ten generuje naturalne zapotrzebowanie na różne innowacje finansowe w zakresie: dywersyfikacji, zabezpieczenia ryzyka rynkowego (instrumenty pochodne), zwiększania płynności/finansowania (sekurytyzacja), transferu ryzyka kredytowego (kredytowe instrumenty pochodne) czy segregacji ryzyka na różnej 
jakości klasy aktywów w celu dostosowania do zindywidualizowanego charakteru inwestorów. Doświadczenie kryzysu skłania wielu naukowców do wniosku, że jedną z głównych jego przyczyn były innowacje finansowe. Fluktuacje na rynkach finansowych stały się rozleglejsze i częstsze, a systemy finansowe niestabilne.

Rozważa się m.in. powrót do koncepcji zapoczątkowanej spektakularnie ustawą Glass-Steagall Act z 1933 roku, która zmuszała banki do zaniechania działalności inwestycyjnej lub wydzielenia jej ze swoich struktur. Szczególnym zadaniem komisji było wskazanie strukturalnych przedsięwzięć reformujących system bankowy, w tym próba rozdzielenia funkcji bankowości detalicznej i inwestycyjnej. Vickers pisze o odgrodzeniu (ring-fencing) działalności detalicznej ważnych systemowo banków oraz o konieczności wzmocnienia bazy kapitałowej, w tym o zaostrzeniu wymogów obowiązujących w bankowości detalicznej. Kapitał własny ważnych systemowo, odgrodzonych banków będzie musiał wynosić co najmniej 10\% aktywów ważonych ryzykiem. Według zaleceń zawartych w raporcie działalność detaliczna, w tym również obsługa małych przedsiębiorstw, miałaby się znaleźć ,wewnątrz ogrodzenia", działalność inwestycyjna natomiast (transakcje z użyciem produktów pochodnych, gwarantowanie ofert sprzedaży papierów wartościowych) miałaby się znaleźć poza nim [ICB 2011]. W 2012 roku w Komisji Europejskiej powołana została grupa pod przewodnictwem Erkki Liikanena [High-level Expert Group..., 2012], która miała za zadanie wskazanie reform sektora bankowego w celu poprawy ochrony ich klientów.

Badania Schmida i Waltera [2009], Acharyi i in. [2006] oraz Laevena i Levine’a [2007] potwierdzają, że zwiększona złożoność generuje koszty agencji, które wykraczają poza wszelkie korzyści wynikające z dywersyfikacji portfela. Szacunki DeYounga i Torny [2013] przeprowadzone na próbie banków amerykańskich działających w latach 2008-2010 pokazują, że prawdopodobieństwo wystąpienia bankructwa banku spada wraz ze wzrostem angażowania banków w działalność maklerską i ubezpieczeniową, ale rośnie w przypadku sekurytyzacji czy venture capital. Z kolei Damankah i in. [2014] zauważyli, że gdy bank uzyskuje relatywnie większe zyski z tytułu marży odsetkowej, pozostaje mniej zaangażowany w dywersyfikowanie swojego portfela $\mathrm{w}$ działalność nietradycyjną (tym samym unika nadmiernego ryzyka. Z kolei Chronopoulos, Girardone i Nankervis [2015] przeprowadzili rozległe badania nad oceną efektywności europejskich banków komercyjnych i wskazali, że dywersyfikacja działalności bankowej znacząco i pozytywnie wpływa na ich efektywność. Podobnie Peng i in. [2017] badali wpływ działalności bancassurance na Tajwanie w 2004 roku i stwierdzili, że banki bardziej zaangażowane w tego typu działalność wykazują tendencję do poprawy efektywności, a także osiągają większe zyski.

Wydaje się, że w nawiązaniu do obecnie tworzonych regulacji ostrożnościowych nad ryzykiem systemowym, analizy znaczenia sektora finansowego oraz licznych sieci powiązań w jego strukturach, powinny uwzględniać: 
- zabezpieczenie płynności dla sektora finansowego. Obecnie banki centralne nie panują nad nadpłynnością sektora finansowego i przenikaniem pieniądza poza granice regulowanego sektora finansowego,

- transformację ryzyka z podmiotów bankowych na strefy bankowości równoległej, tzw. shadow banking,

- zaangażowanie w rynki instrumentów pochodnych, szczególnie dotyczy to sytuacji w podmiotach spekulujących, czyli niezamykających pozycji finansowych [Karkowska 2015].

Fernandez i González [2005] uważają, że rygorystyczne wymogi kapitałowe zmniejszają ryzyko bankowe. Z kolei Barth i in. [2006; 2013] wskazują, że ograniczenie działalności banku przez regulacje nadzorcze wpływa ujemnie na stabilność sektora bankowego i zwiększa prawdopodobieństwo wystąpienia kryzysu. Natomiast Demirgüç-Kunt i Huizinga [2009] dowodzą, że strategie bankowe, które polegają na generowaniu dochodów nieodsetkowych lub wykorzystują finansowanie bez udziału depozytów, są przyczyną niestabilności finansowej. Acharya [2009] zauważa, że banki inwestują w mocno skorelowane aktywa, ponieważ ich właściciele ze względu na ograniczoną odpowiedzialność nie internalizują kosztów bankructwa. Badania nie dostarczyły jednoznacznych odpowiedzi na pytania dotyczące wpływu restrykcyjności regulacji nadzorczych na ryzyko systemowe w krajach europejskich.

\section{Charakterystyka danych i model badawczy}

W celu weryfikacji pytania badawczego: $w$ jakim zakresie dywersyfikacja działalności banków komercyjnych poprzez wchodzenie w różne segmenty rynku wpływa na ich stabilność, został oszacowany model, w którym uzależniono stabilność ban$\mathrm{ku}$ mierzoną wskaźnikiem $Z S C O R E_{n, i, t}$ od zmiennych prezentujących dochody z działalności tradycyjnej i nietradycyjnej banku. Analiza została poszerzona o czynniki specyficzne dla danego kraju, tj. restrykcyjność regulacji bankowych, jakość monitoringu inwestorów oraz skuteczność działania nadzoru finansowego, które mają wpływ na zmiany w nietradycyjnej działalności banków definiujących regulacje i nadzór sektora bankowego - REGULATION ${ }_{i, p}$ oraz wpływ regulacji na wynik pozaodsetkowy - REGULATION * NONII ${ }_{n, i, t^{\circ}}$ :

$$
\begin{gathered}
\text { ZSCORE }_{n, i, t}=\beta_{0}+\beta_{1} \text { ZSCORE }_{n, i, t-q}+\beta_{2} \text { NONII }_{n, i, t}+\beta_{3} \text { REGULATION }^{2} \text { NONII }_{n, i, t}+ \\
\beta_{4} \text { REGULATION } \\
i, t+\beta_{5} \text { NII }_{n, i, t}+\beta_{6} \sum_{k} \text { BANKRISK }_{n, i, t}^{k}+\beta_{7} \text { GDP }_{i, t}+ \\
\beta_{8} \text { UNEMPLOY }_{i, t}+\beta_{9} D U M_{-} \text {TIME }_{n, i}+\varepsilon_{i, t}
\end{gathered}
$$

gdzie: ZSCORE ${ }_{n, i, t}$ - wskaźnik Z-score kalkulowany według formuły (II) dla każdego banku $n$, w kraju $i$, w czasie $t$, opisany formułą: 


$$
\operatorname{ZSCORE}_{n, i, t}=\frac{\left(\frac{E_{n, i, t}}{T A_{n, i, t}}+R O A_{n, i, t}\right)}{\sigma\left(R O A_{n, i, t}\right)},
$$

gdzie: ZSCORE $E_{n, i, t}$ - jest miarą Z-score dla banku $n$, w kraju $i$, w czasie $t ; E_{n, i, t}-$ kapitały własne banku $n$, w kraju $i$, w czasie $t ; T A_{n, i, t}$ - wskaźnik aktywa banku $n$, w kraju $i$, w czasie $t ; \frac{E_{n, i, t}}{T A_{n, i, t}}-$ wskaźnik kapitałowy banku $n$, w kraju $i$, w czasie $t$; $R O A_{n, i, t}$ - wskaźnik rentowności na aktywach banku $n$, w kraju $i$, w czasie $t$; $\sigma\left(R O A_{n, i, l}\right)$ - odchylenie standardowe wskaźnika rentowności $R O A$ w banku $n, \mathrm{w}$ kraju $i$, w okresie wszystkich lat analizy, tj. 1996-2011.

$N_{N N I I_{n, i t}}$ - wynik pozaodsetkowy do wyniku na działalności operacyjnej w banku $n$, w kraju $i$, w czasie $t$. Wskazanej zmiennej użyli w swoich badaniach również Lepetit i in. [2007], De Jonghe i in. [2015], Stiroh i Rumble [2006], Meslier i in. [2014] oraz Mostak [2017]; $N_{n} I_{n, i, t}$ - wynik odsetkowy do wyniku na działalności operacyjnej banku $n$, w kraju $i$, w czasie $t ; B A N K R I S K_{n, i, t}$ - wektor zmiennych niezależnych wskazujących na ryzyko specyficzne dla banku $n$, w kraju $i$, w czasie $t$; BANKRISK $=$ [LLP, DEPO_LOAN], gdzie: $L L P_{n, i, t}-$ udział rezerw na kredyty zagrożone do wielkości udzielonych kredytów w banku $n$, w kraju $i$, w czasie $t$, przyjęty jako miara ryzyka kredytowego; $D E P O_{-} L O A N_{n, i, t}$ - wskaźnik depozytów do kredytów banku $n$, w kraju $i$, w czasie $t$, przyjęty jako miara płynności banku; $G D P_{i, t}$ - roczna stopa wzrostu realnego PKB w kraju $i$, w czasie $t$; UNEMPLOY ${ }_{i, t}$ - stopa bezrobocia w kraju $i$, w czasie $t$; REGULATION $N_{i, t}$ - zmienne wskazujące na restrykcyjność regulacji i nadzoru nad bankami w kraju $i$, w czasie $t$, określone czteremi indeksami opracowanymi przez Bartha i in. [2006; 2013], w tym: SECURE_ACT $T_{i, t}$ - indeks wskazujący zakres, w jakim banki mogą angażować się w działalność nietradycyjną, tj. gwarantowanie emisji, pośrednictwo i obrót papierami wartościowymi, oraz inną działalność na rynku kapitałowym, w szczególności w branży funduszy inwestycyjnych; indeks przyjmuje wartość 1-4, im wyższa wartość indeksu, tym bardziej restrykcyjne zasady; BANK_RESTRICT $T_{i, t}$ - indeks restrykcyjności regulacji bankowych; indeks przyjmuje wartość 3-12, im wyższa wartość indeksu, tym bardziej restrykcyjne zasady; SUPERVISOR ${ }_{i, t}$-indeks skuteczności nadzoru finansowego; indeks przyjmuje wartość 1-14, im wyższa wartość indeksu, tym większa siła nadzoru; PRIVMON ${ }_{i, t}$ - indeks monitoringu przez prywatnych inwestorów; indeks przyjmuje wartość 1-12, im wyższa wartość indeksu, tym większy monitoring.

W modelu zostały uwzględnione zmienne makroekonomiczne dla porównania wpływu, jaki może stanowić cykliczność w stabilności banków komercyjnych.

Ze względu na obecność danych czasowo-przestrzennych wykorzystano dwustopniowy estymator GMM Blundella i Bonda [1998]. Przy wykorzystaniu zbioru 
danych, który obejmuje ok. 11000 banków (w budowaniu panelu zostały uwzględnione jedynie te szeregi, które miały ponad 75\% obserwacji w latach 1996-2011), wyniki empiryczne wykazały ogólny obraz uzależnienia stabilności finansowej od działalności nietradycyjnej banków i jej wpływu na ryzyko niestabilności w sektorze bankowym. W badaniu zostały wykorzystane dane ze sprawozdań finansowych banków $\mathrm{z}$ bazy Bankscope.

Statystyka opisowa dla zmiennych bankowych, makroekonomicznych oraz zmiennych wskazujących na restrykcyjność regulacji i nadzoru nad bankami w kraju $i$, w czasie $t$, określona czterema indeksami opracowanymi przez Bartha i in. [2006; 2013], została zaprezentowana w tabeli 1.

Tabela 1. Statystyka opisowa

\begin{tabular}{|l|r|r|r|r|r|}
\hline \multicolumn{7}{|c|}{ Statystyka opisowa dla całej próby (\# obs. 83282) } \\
\hline & Średnia & Mediana & OdchStan. & 30 percentyl & 70 percentyl \\
\hline ZSCORE & 23,71 & 17,61 & 23,13 & 8,61 & 31,98 \\
\hline NONII & 0,15 & 0,11 & 0,49 & 0,07 & 0,18 \\
\hline NII & 0,85 & 0,89 & 0,49 & 0,82 & 0,93 \\
\hline LLP & 0,02 & 0,00 & 0,81 & 0,00 & 0,01 \\
\hline DEPO_LOAN & 3,22 & 1,26 & 28,59 & 1,05 & 1,57 \\
\hline GDP & 2,16 & 2,53 & 2,75 & 0,98 & 3,79 \\
\hline UNEMPLOY & 6,83 & 5,80 & 3,08 & 4,64 & 8,60 \\
\hline SECUR_ACT & 1,88 & 2,00 & 0,72 & 1,00 & 2,00 \\
\hline BANK_RESTRICT & 7,18 & 8,00 & 1,87 & 6,00 & 8,00 \\
\hline SUPERVISOR & 11,78 & 13,00 & 2,56 & 10,00 & 13,00 \\
\hline PRIVMON & 8,56 & 9,00 & 1,43 & 8,00 & 10,00 \\
\hline
\end{tabular}

Objaśnienia: ZSCORE - zmienna objaśniana, kalkulowana wg wzoru (I), mierzona liczbą odchyleń standardowych rentowności banku, która spowoduje całkowitą absorpcję kapitałów własnych banku i doprowadzi do jego upadłości, NONII - wynik pozaodsetkowy do wyniku na działalności operacyjnej banku, NII - wynik odsetkowy do wyniku na działalności operacyjnej banku, LLP - udział rezerw na kredyty zagrożone do wielkości udzielonych kredytów, DEPO_LOAN- wskaźnik depozytów do kredytów banku, GDP - roczna stopa wzrostu realnego PKB (w \%), UNEMPLOY - stopa bezrobocia (w \%); SECUR_ACT - indeks wskazujący zakres, w jakim banki mogą angażować się w działalność nietradycyjną, tj. gwarantowanie emisji, pośrednictwo i obrót papierami wartościowymi, oraz inną działalność na rynku kapitałowym, w szczególności branży funduszy inwestycyjnych, BANK_RESTRICT - indeks restrykcyjności regulacji bankowych, SUPERVISOR - indeks skuteczności nadzoru finansowego, PRIVMON - indeks monitoringu przez prywatnych inwestorów.

Źródło: opracowanie własne na podstawie danych OECD Statistics oraz indeksów [Barth i in. 2006; 2013]. 


\section{Wyniki}

Wyniki szacunków Modelu (I) zostały zaprezentowane w czterech kategoriach wpływu następujących zmiennych regulacyjnych: SECUR_ACT, która jest miarą

Tabela 2. Wyniki szacunku modelu wpływu wyników pozaodsetkowych banku na jego stabilność w kontekście restrykcyjności regulacji bankowych

\begin{tabular}{|c|c|c|c|c|}
\hline & Model I.1 & Model I.2 & Model I.3 & Model I.4 \\
\hline & ZSCORE & ZSCORE & ZSCORE & ZSCORE \\
\hline \multirow[t]{2}{*}{ SECUR_ACTxNONII } & 0,035 & & & \\
\hline & $(1,34)$ & & & \\
\hline \multirow[t]{2}{*}{ SECUR_ACT } & $-2,732^{*}$ & & & \\
\hline & $(-1,68)$ & & & \\
\hline \multirow[t]{2}{*}{ BANK_RESTRICTxNONII } & & $-0,139^{*}$ & & \\
\hline & & $(1,85)$ & & \\
\hline \multirow[t]{2}{*}{ BANK_RESTRICT } & & $0,965^{* *}$ & & \\
\hline & & $(-2,57)$ & & \\
\hline \multirow[t]{2}{*}{ SUPERVISORxNONII } & & & $0,061^{*}$ & \\
\hline & & & $(1,67)$ & \\
\hline \multirow[t]{2}{*}{ SUPERVISOR } & & & $0,168^{* *}$ & \\
\hline & & & $(-0,55)$ & \\
\hline \multirow[t]{2}{*}{ PRIVMONxNONII } & & & & $-0,038^{* *}$ \\
\hline & & & & $(-0,60)$ \\
\hline \multirow[t]{2}{*}{ PRIVMON } & & & & $-0,606^{*}$ \\
\hline & & & & $(1,13)$ \\
\hline \multirow[t]{2}{*}{ constant } & $4,711^{* * *}$ & $4,739^{* * *}$ & $2,656^{* * *}$ & $3,571^{* * *}$ \\
\hline & $(1,60)$ & $(1,27)$ & $(1,24)$ & $(1,68)$ \\
\hline Liczba obserwacji & 67525 & 67733 & 68394 & 67068 \\
\hline Liczba banków & 9355 & 9366 & 9391 & 9280 \\
\hline $\mathrm{AR}(1)$ & $-2,451^{* *}$ & $-2,334^{*}$ & $-2,368^{*}$ & $-2,563^{* * *}$ \\
\hline $\mathrm{AR}(2)$ & $-1,143$ & $-0,541$ & $-0,397$ & $-0,687$ \\
\hline Hansen test & 596,566 & $542,528^{*}$ & 498,990 & $623,046^{*}$ \\
\hline
\end{tabular}

Objaśnienia: NONII - wynik pozaodsetkowy do wyniku na działalności operacyjnej banku, NII - wynik odsetkowy do wyniku na działalności operacyjnej banku, SECUR_ACT - indeks wskazujący zakres, w jakim banki mogą angażować się w działalność nietradycyjną, tj. gwarantowanie emisji, pośrednictwo i obrót papierami wartościowymi, oraz inną działalność na rynku kapitałowym, w szczególności branży funduszy inwestycyjnych, BANK_RESTRICT - indeks restrykcyjności regulacji bankowych, SUPERVISOR - indeks skuteczności nadzoru finansowego, PRIVMON - indeks monitoringu przez prywatnych inwestorów; symbole * dla $p<0,10, * * p<0,05, * * * p<0,01$ oznaczają poziomy istotności; w nawiasie statystyka t; AR(1) i AR(2) oznaczają wartości empiryczne testu na autokorelację reszt Arellano-Bonda, odpowiednio 1 i 2 rzędu dla hipotezy zerowej H0: autokorelacja pierwszego (drugiego) rzędu nie występuje. Test Hansena oznacza wartości empiryczne testu Hansena dla hipotezy zerowej H0: warunki ponadidentyfikujące są poprawne (instrumenty są właściwe).

Źródło: opracowanie własne na podstawie danych bazy Bankscope. 
zakresu, w którym banki mogą angażować się w działalność nietradycyjną, tj. gwarantowanie emisji, pośrednictwo finansowe i obrót papierami wartościowymi, oraz inne aspekty działalności inwestycyjnej bliskie branży funduszy inwestycyjnych, BANK_RESTRICT, która wskazuje na poziom ogólnych restrykcji regulacyjnych, nakładanych na działalność bankową w danym kraju, SUPERVISOR, badającej siłą/prawem organów nadzorczych do podjęcia konkretnych działań w celu zapobiegania i usuwania problemów w sektorze finansowym, oraz PRIVMON - indeks monitoringu firm przez prywatnych inwestorów. Wyniki zostały zaprezentowane w tabeli 2.

\section{Wnioski}

Wyniki potwierdziły istotną statystycznie zależność między stabilnością banków a ich wynikiem odsetkowym NII i pozaodsetkowym NONII. Zależność jest negatywna dla wyniku nieodsetkowego i pozytywna dla wyniku odsetkowego. Należy również zauważyć, że banki w okresie analizy mogły mieć problem z zarządzaniem ryzykiem kredytowym, na co wskazuje istotna statystycznie i ujemna wartość współczynnika przy zmiennej LLP oraz ryzyka płynności (ujemna wartość współczynnika przy zmiennej DEPO_LOAN).

Pytanie szczegółowe, jakie zostało postawione w niniejszym badaniu, a dotyczące znaczenia czynników specyficznych dla danego kraju, tj. restrykcyjności regulacji bankowych, jakości monitoringu inwestorów oraz skuteczności działania nadzoru finansowego w budowaniu stabilności banków, zostało poddane weryfikacji w modelach (I.1)-(I.4) w tabeli 2.

Należy zauważyć, że w modelach (I.1)-(I.4) fakt istnienia regulacji i nadzoru państwowego i prywatnego $\mathrm{w}$ wielu przypadkach nie ma statystycznie istotnego wpływu na stabilność banków komercyjnych. W przypadkach statystycznie istotnych kierunek oddziaływania wskazanych zmiennych podlega modyfikacjom. Jednak wprowadzenie do modeli pewnych modyfikacji w postaci interakcji pomiędzy zmiennymi regulacyjnymi a wynikiem pozaodsetkowym banków NONII ujawnia kilka interesujących i ważnych wniosków. Szacunki wpływu kolejnych zmiennych regulacyjnych wykazały, że wzrost zakresu, w którym banki mogą angażować się w działalność nietradycyjną, mierzone indeksem SECUR_ACT, osłabia stabilność banków $-2,732$. Z kolei wzrost poziomu ogólnych restrykcji regulacyjnych nakładanych na działalność bankową w danym kraju działa stabilizująco na banki: BANK_ RESTRICT $+0,965$, ale $\mathrm{w}$ odniesieniu konkretnie do wyniku pozaodsetkowego banków osłabia ją: BANK_RESTRICTxNONII -0,139. Kolejne indeksy, badające siłę organów nadzorczych do podjęcia konkretnych działań w celu zapobiegania i usuwania problemów w sektorze finansowym SUPERVISOR -0,168, oraz indeks monitoringu firm przez prywatnych inwestorów PRIVMON -0,606 wpływają negatywnie na stabilność banków jako całości. Natomiast należy podkreślić, że w odniesieniu do działalności nietradycyjnej banków nadzór państwowy działa sta- 
bilizująco na ich kondycję SUPERVISORxNONII: +0,061, natomiast monitoring prywatnych inwestorów negatywnie: PRIVMONxNONII -0,038.

Badanie potwierdziło zasadność działań sugerowanych w raporcie Vickersa z 2011 roku oraz grupy Liikanena z 2012 roku, zmierzających do wydzielenia ze struktur bankowych działalności inwestycyjnej i próby rozdzielenia funkcji bankowości detalicznej i inwestycyjnej.

\section{Literatura}

Acharya V., 2009, A theory of systemic risk and design of Prudential Bank regulation, Journal of Financial Stability, vol. 5(3), s. 224-255.

Acharya V., Hasan I., Saunders A., 2006, Should banks be diversified? Evidence from individual bank loan portfolios, Journal of Business, no. 79, s. 1355-1412.

Barth J.R., Caprio G. Jr., Levine R., 2006, Rethinking Bank Regulation. Till Angels Govern, Cambridge University Press, New York.

Barth J.R., Lin Ch., Ma Y., Seade J., Song F.M., 2013, Do bank regulation, supervision and monitoring enhance or impede bank efficiency?, Journal of Banking and Finance, no. 37, s. 2879-2892.

Blundell R., Bond S., 1998, Initial conditions and moment restrictions in dynamic panel data models, Journal of Econometrics, no. 87, s. 11-143.

Chronopoulos D.K., Girardone C., Nankervis J.C., 2015, Double bootstrap confidence intervals in the two-stage DEA approach, Journal of Time Series Analysis, no. 36, s. 653-662.

Damankah S.B., Anku-Tsede O., Amannkwaa A., 2014, Analysis of non-interest income of commercial banks in Ghana, International Journal of Academic Research in Accounting, Finance and Management Sciences, vol. 4(4), s. 263-271.

De Jonghe O., Diepstraten M., Schepens G., 2015, Banks'size, scope and systemic risk: What role for conflicts of interest?, Journal of Banking and Finance, no. 61, s. S3-S13.

Demirgüç-Kunt A., Huizinga H., 2009, Determinants of commercial bank interest margins and profitability: Some international evidence, The World Bank Economic Review, vol. 13, s. 430-455.

DeYoung R., Torna G., 2013, Nontraditional banking activities and bank failures during the financial crisis, Journal of Banking and Finance, no. 22, s. 397-421.

Fernandez A., González F., 2005, How accounting and auditing systems can counteract risk-shifting of safety nets in banking: Some international evidence, Journal of Financial Stability, no. 1, s. 466-500.

High-level Expert Group on Reforming the Structure of the EU Banking Sector 2012, Final Report. Chaired by Erkki Liikanen, Brussels.

ICB, 2011, Final Report Recommendations, Independent Commission on Banking, London.

Karkowska R., 2015, Ryzyko systemowe. Charakter i źródła indywidualizacji w sektorze bankowym, Wolters Kluwer, Kraków.

Laeven L., Levine R., 2007, Is there a diversification discount in financial conglomerates?, NBER Working Paper Series, Working Paper 11499 http://www.nber.org/papers/w11499.

Lepetit L., Nys E., Rous P., Tarazi A., 2007, Bank income structure and risk: An empirical analysis of European banks, Journal of Banking and Finance, no. 32, s. 1452-1467.

Meslier C., Tacneng R., Tarazi A., 2014, Is bank income diversification beneficial? Evidence from an emerging economy, Journal of International Financial Markets, Institutions and Money, no. 31, s. 97-126.

Mostak A., 2017, Asset quality, non-interest income, and bank profitability: Evidence from Indian banks, Economic Modelling, no. 63, s. 1-14. 
Peng J.-L., Jeng V., Wang J.L., Chen Y.-C., 2017, The impact of bancassurance on efficiency and profitability of banks: Evidence from the banking industry in Taiwan, Journal of Banking and Finance, vol. 80, s. 1-13, https://doi.org/10.1016/j.jbankfin.2017.03.013.

Schmid M., Walter I., 2009, Do financial conglomerates create or destroy economic value?, Journal of Financial Intermediation, no. 18, s. 193-216.

Stiroh K., Rumble A., 2006, The dark side of diversification: The case of US financial holding companies, Journal of Banking and Finance, vol. 30(8), s. 2131-2161. 